\title{
Echoic Object Recognition by the Bottlenose Dolphin
}

\author{
Heidi E. Harley \\ New College of Florida \\ The Seas ${ }^{\circledR}$, Epcot, Walt Disney World ${ }^{\circledR}$ Resort \\ Caroline M. DeLong \\ University of Hawaii
}

\begin{abstract}
Object recognition, essential to many animals, often occurs underwater and in poor visibility conditions for bottlenose dolphins. Bottlenose dolphins can use sound through their ability to echolocate in order to recognize objects. Echoic object recognition is an unusual faculty that offers rich research opportunities and is the focus of this article. This review begins with a brief overview of the dolphin's echolocation system followed by considerations of echoic object discrimination, echoic object constancy, the use of echo trains versus individual echoes for object recognition, and extraction of object feature information from echoes. The authors present new data relating the acoustic analysis of objects with a dolphin's ability to recognize those objects. The results highlight the potential uses for simultaneous analysis of acoustic and behavioral data in order to understand better which features of echoes and echo trains allow the dolphin to recognize objects across vision and echolocation.
\end{abstract}

Keywords: Echolocation, Dolphin, Object recognition, Biosonar

Most animals rely on object recognition for survival. They must recognize predators and prey, familiar and unfamiliar surroundings, potential mates and rivals, and more. Studies of visual object recognition are most common, but animals also use sound to identify objects around them. Atlantic

Heidi E. Harley, Division of Social Sciences, New College of Florida; Caroline M. DeLong, Hawaii Institute of Marine Biology, University of Hawaii.

Caroline M. DeLong is now at the Department of Neuroscience, Brown University.

This work was supported in part by a grant from Walt Disney World ${ }^{\circledR}$ Resort to the first author. We thank Herb Roitblat, Whit $\mathrm{Au}$, Gordon Bauer, and Wendi Fellner for discussions and suggestions; Whit Au and Kelly Benoit-Bird for their assistance in making the acoustic measurements of the objects; David W. Lemonds for writing the Matlab program to measure echo features; and the trainers and staff at Epcot ${ }^{\mathbb{B}}$ s Seas for their assistance in conducting the object discrimination study with the dolphin.

Correspondence concerning this article should be addressed to Heidi E. Harley, Division of Social Sciences, New College of Florida, 5800 Bay Shore Road, Sarasota, Florida 34243. E-mail: harley@ncf.edu bottlenose dolphins (Tursiops truncatus, the most studied cetacean, hereafter referred to simply as "dolphin") live in protected, biologically rich, typically murky coastal waters in which it is often hard to see. However, sound travels very efficiently in water, and dolphins evolved to take advantage of this fact by developing a sound-based system, echolocation, to investigate their world.

Exactly how the dolphin puts its echolocation system to use remains somewhat mysterious. There are more hypotheses about these uses than there are clear conclusions. Potential uses include detection and recognition of prey species (probably based on their air-filled swim bladders), other dolphins, and navigational identifiers in addition to possibly being a communicative tool (Brownlee \& Norris, 1994). For communication, dolphins also emit narrow-band whistles and very short, broadband burst-pulse sounds. Work with dolphins in laboratories confirms that the dolphin's echolocation system is finely tuned for detection of small acoustic differences in echoes returning from the environment, and this precision suggests that echolocation is useful in multiple ways including object recognition.

Object matching studies with dolphins verify that dolphins 
can in fact recognize objects using echolocation. Their ability to accomplish this feat is remarkable given the responsiveness of sound to myriad factors including air bubbles, temperature, salinity, density, ambient surfaces, and the multiple surfaces presented by an echolocated object itself. Indeed, echoes from different aspects of a one object can vary more from each other than do echoes from different objects (DeLong, Au, Lemonds, Harley, \& Roitblat, 2006). These complications have made it very difficult, for example, for the U.S. Navy to a create a sonar system that recognizes objects as well as dolphins do, a goal that has led to many studies of dolphin echolocation in order to aid in the design of a man-made system that can mimic the dolphin. To date, no such system is available. The best sonar systems continue to exist only in cetaceans.

In this review we will briefly describe the dolphin's echolocation system and then focus on the data relating to echoic object recognition by the dolphin.

\section{The dolphin's echolocation system}

To echolocate, dolphins produce clicks and receive click echoes that they process in order to recognize objects. (See $\mathrm{Au}, 1993$, for a comprehensive review of the dolphin sonar system.) Dolphin echolocation clicks are very short (40-70 $\mu \mathrm{s})$, loud (180-225 dB re $1 \mu \mathrm{Pa}$ at $1 \mathrm{~m}$ ), broadband emissions produced within the head and emitted in a focused beam of about 10 degrees in the vertical and horizontal planes ( $\mathrm{Au}$, 1993). When echolocating an object, a dolphin typically produces one click and receives the ensuing echo before producing another click. The dolphin produces these clicks in a train. The inter-click interval is usually the two-way travel time for the sound to move between the dolphin and the echolocated object plus between 19 to $45 \mathrm{~ms}$, time presumably used for processing ( $\mathrm{Au}, 1993)$. When a dolphin is performing a detection task in which a stimulus object is either present or absent, the inter-click interval when the target is absent is at least as long as the two-way travel time at the distance at which the target would normally appear, thereby suggesting that the dolphin expects the echo to arrive within a certain time interval (Au, Floyd, Penner, \& Murchison, 1974; Au, Penner, \& Kadane, 1982).

Although echolocation click types vary across individual dolphins (Houser, Helweg, \& Moore, 1999), and clicks produced by individuals cluster around different peak frequencies (Houser, Martin, Bauer, Phillips, Herrin, Cross, Vidal, \& Moore, 2005), the causes for these variations (e.g., individual preference, task type, hearing abilities, differential morphology) are not usually clear. In echolocation tasks, dolphins appear to vary their clicks in order to get better information about objects. For example, they can increase echo ampli- tudes by producing more intense clicks or by getting closer to objects without changing click source levels (Houser et al., 2005). In noisy environments, dolphins tend to produce louder clicks that have higher peak frequencies (Au et al., 1974) and to produce more clicks (Au et al., 1982).

Bottlenose dolphins have impressive sound processing capabilities for decoding echoes. (See Branstetter \& Mercado, 2006, for a concise review of sound processing and use by cetaceans.) Compared to most mammals, dolphin brains are specialized for sound processing. For example, the inferior colliculus, one of the major hearing centers, is 40 times larger in the bottlenose dolphin than in humans (Glezer et al., 2004), even though human and dolphin brains are about the same size (Marino, 1998). Dolphins are very sensitive to acoustic differences in frequency, amplitude, and time. They hear across a wide frequency range, from $75 \mathrm{~Hz}$ to $150 \mathrm{kHz}$ (Johnson, 1967), and they can discriminate differences in frequencies of tonal stimuli that only vary by $0.2 \%$ to $0.4 \%$ in the $2-55 \mathrm{kHz}$ range and that vary by less than $1 \%$ up to $140 \mathrm{kHz}$ (Thompson \& Herman, 1975). Dolphins can discriminate intensities in broadband sounds that vary by a small amount - about $1 \mathrm{~dB}$ for signals $36 \mathrm{~dB}$ above threshold (Evans, 1973; Velmin, Titov, \& Yurkevich, 1975 as cited in Au, 1993). They can separate broadband sounds that arrive very closely in time; sounds separated by at least $264 \mu$ s are distinguished as separate sounds (Au, Moore, \& Pawlowski, 1988; Moore, Hall, Friedl, \& Nachtigall,1984).

\section{Echoic object discrimination: Echoic cues}

Most object discrimination tasks performed by echolocating dolphins have been based entirely on sound processing; in these tests the dolphin cannot see the objects and only experiences their echoes. Often the dolphin reports whether or not the echoes match those reflected by a standard target, a consistent $\mathrm{S}+$; the dolphin receives fish reinforcement for indicating the presence of that target and no other. The targets may be engineered to produce echoes that vary in specific ways. Although this method does not always allow us to determine whether or not the dolphin associates these echoes with the objects themselves or their features, these studies have contributed to our understanding of the features of echoes that a dolphin can discriminate. (See Au, 1993, and Nachtigall, 1980, for reviews of many of these studies.) For example, dolphins have discriminated among planar targets that varied only in size and produced echoes varying by $1 \mathrm{~dB}$ re $1 \mu \mathrm{Pa}$ (Barta, 1969). From this study we can determine that dolphins are able to use small intensity differences to discriminate echoes, but we do not know if the dolphin recognized that the stimuli that produced the echoes were identical in every way but size. 
Not only can dolphins use intensity to discriminate echoes, but they also may use frequency differences in the echoes. In one experiment, a dolphin discriminated between cylinders, presented two at a time, that varied only in material (aluminum vs. stainless steel and aluminum vs. coral rock) (Au \& Turl, 1991). Discrimination of the aluminum and coral rock cylinders was tested at novel orientations, and the dolphin continued to discriminate the stimuli. Echoes from the objects were complex and had different amplitude peaks, called highlights, visible in the echoes' waveforms. (See Figure 1 for echo highlights in a waveform.) These highlights returned to the dolphin at different times, usually less than $264 \mu$ s apart (the interval at which dolphins hear more than one sound; Au et al., 1988; Moore et al., 1984).

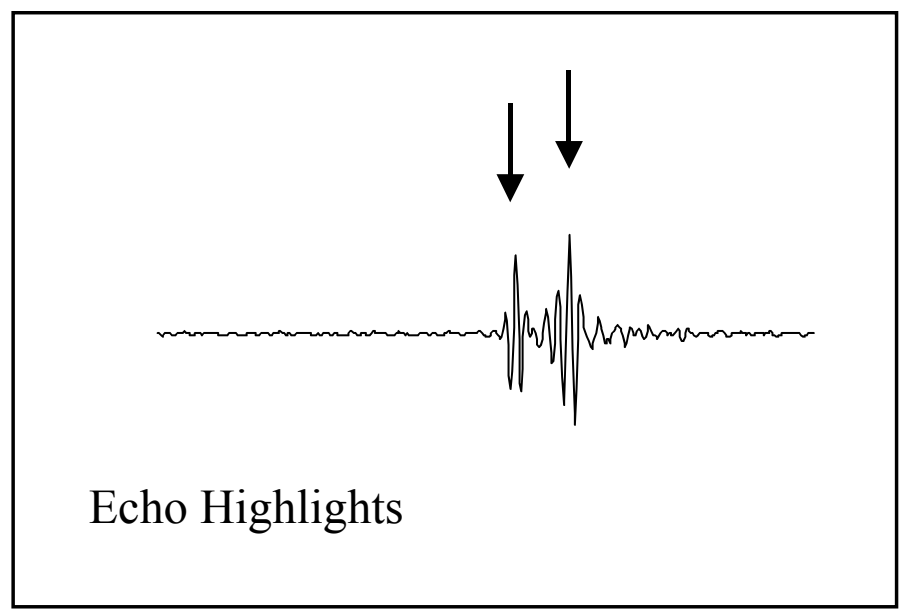

Figure 1. Echo highlights in a waveform (time on horizontal axis, amplitude on vertical axis).

The echo highlights may be heard as different pitches via a phenomenon similar to time-separation pitch (TSP) (Au \& Hammer, 1980; Hammer \& Au, 1980) that occurs when humans hear correlated broadband pulses that arrive very closely together in time (McClellan \& Small, 1965). When humans are tested for TSP, they match pure tones to the TSP sounds to which they have listened. In dolphins, perception of TSP was inferred from their ability to discriminate between rippled (correlated noise bursts) and non-rippled noise, stimuli used in human tests of TSP (Au \& Pawloski, 1989). Potential TSP cues often vary between echoes generated by different objects including aluminum cylinders that vary in wall thickness by less than $0.3 \mathrm{~mm}$ (Au \& Pawloski, 1992). Humans listening to echoes that were stretched out in time to reduce their frequency into the human hearing range discriminated among targets using duration cues, TSP, and click pitch (Au \& Martin, 1989).

Although humans and dolphins clearly have different sound processing apparatus, human listeners have been test- ed in several studies in order to suggest potential cues that dolphins could possibly use for echoic discrimination tasks. For example, DeLong, Au, and Stamper (2007) echolocated aspect-independent objects with dolphin-like signals and then recorded the echoes produced by each object. Humans listened to these echoes after they had been time-stretched by a factor of 167 in order to reduce their center frequencies from about $120 \mathrm{kHz}$ to $719 \mathrm{~Hz}$, a frequency easily heard by humans. The objects, which had been used in discrimination studies with dolphins, varied in specific ways: hollow aluminum cylinders varied only in wall thickness (a standard had a $6.35 \mathrm{~mm}$ wall thickness and eight others varied by \pm 0.2 , $\pm 0.3, \pm 0.4, \pm 0.8 \mathrm{~mm}$ ) and solid $7.62 \mathrm{~cm}$-diameter spheres varied only in material (a standard was stainless steel and the four others were aluminum, brass, glass, nylon). Like the dolphins, the human subjects discriminated between echoes from the standard objects and the comparisons within each set, but the humans also identified which comparison object produced the echoes. The human and dolphin subjects performed similarly in most discriminations. The humans reported using pitch (potentially TSP) and duration to identify the cylinders and using pitch and timbre to identify the spheres. Neural network models using echoes from the cylinders classifed them using frequency information, although better discrimination resulted from use of both time and frequency information (Au, Andersen, Rasmussen, Roitblat, \& Nachtigall, 1995).

In another study, human listeners were presented with echoes from different angles of aspect-dependent objects that had been used in a dolphin discrimination task (DeLong, Au, Harley, Roitblat, \& Pytka, 2007). Aspect-dependent objects (versus aspect-independent objects, e.g., a sphere) appear different based on their orientation, and echoes from different angles differ substantially. The objects in the six object sets varied in size, shape, material, and/or texture (e.g., three stone squares varied in size but had the same shape and material). In two experiments, the human listeners performed as well or better than the dolphin at discriminating objects and reported the salient acoustic cues. Instead of comparing overall discrimination ability as in previous studies, the authors compared the error patterns (object confusions) of the humans and the dolphin to determine which acoustic features reported by the humans were likely to have been used by the dolphin. When the humans and the dolphin confused the same objects, it implied that they may have used the same acoustic features. Conversely, when they did not confuse the same objects, it implied they may have used different acoustic features. The results indicated that the dolphin did not appear to use overall echo amplitude but that it attended to the pattern of changes in the echoes across different object orientations. Having information in multiple echoes gleaned from multiple object orientations appeared to be particularly 
advantageous when discriminating among objects that varied in shape.

\section{Echoic object constancy}

As in visual perception of objects by humans, dolphins appear to experience object constancy when they echolocate objects even though the returning echoes are highly variable. Sound in water travels very fast (about $1522 \mathrm{~m} / \mathrm{s}$ in sea water at $20^{\circ} \mathrm{C}$, salinity $3.5 \%$, pressure $0.1 \mathrm{MPa}$ ), more than four times faster than in air, and is affected by thermoclines, waves, bubbles, bottom topography, surface bounce, biological noise such as that produced by snapping shrimp, wind, rain, pressure, and more. However, even with this variation, dolphins can successfully perform echoic object recognition tasks. These tasks are typically matching-to-sample tasks in which an animal is rewarded for choosing an object from among an array of two or more objects that is (usually) identical to a sample object previously (or simultaneously) experienced by the animal. For example, the animal may experience a sphere and then be rewarded for choosing the sphere from among an array of several objects, e.g., a sphere, a cylinder, and a pyramid. Matching tasks differ from tasks in which the animal always responds only to a single standard in that an animal in a matching task must recognize a number of objects presented within a group whereas an animal that identifies a single object may categorize objects into two categories: the standard and not-the-standard. In this case, a very specific feature of the standard may allow it to be identified. Matching tasks are less likely to be solved using such a pointed criterion.

Dolphins can perform echoic delayed matching-to-sample tasks which suggests that they can recognize objects using echolocation alone. In one such study, a blind-folded adult male dolphin, Rake, correctly chose a matching object from a 3-alternative array with very high accuracy, $94.5 \%$, across many sessions (Roitblat, Penner, \& Nachtigall, 1990). An analysis of the dolphin's clicks to each object revealed that he clicked most often to the stimulus that he was most likely to choose incorrectly, thereby suggesting that he expended more effort to recognize an object that was difficult to identify than was easy to identify (Roitblat et al., 1990). In this case the difficult object was a water-filled stainless steel sphere $5 \mathrm{~cm}$ in diameter. A similar object (though $7.62 \mathrm{~cm}$ in diameter) had been used in a detection experiment and was readily reported as being present at much greater distances (up to 113 meters vs. less than 5 meters in the MTS task) in similar conditions (Au \& Snyder, 1980). This difference between tasks suggests that echoic object discrimination and recognition are much more difficult than object detection (Roitblat et al., 1990). Apparently, recognition of an object requires extraction of more detailed information only avail- able in a strong return signal. In contrast, detection of a very familiar object that is probably fairly unique compared to other objects in the environment is possible with a much weaker return signal. In the matching task, Rake's use of increased clicks to identify a difficult object also suggests that he integrated information across successive echoes from a single object (Roitblat et al., 1990).

As noted earlier in Au and Turl's (1991) cylinder discrimination test, in some circumstances dolphins can recognize objects across different orientations even though echoes change dramatically when orientation changes. Variations of echoes from the same object presented at different orientations can be greater than variations of echoes produced from different objects (DeLong et al., 2006). However, a dolphin successfully performed a matching-to-sample task with aspect-dependent objects (cube, rectangular prism, pyramid) that were hung using a swivel and were free to rotate thereby varying which aspect of the objects faced the dolphin (Helweg, Roitblat, Nachtigall, \& Hautus, 1996). Echo trains returning from the sample object were recorded and analyzed. Relative amplitude and spectral bandwidth (the area of most spectral energy) were significantly different between some of the stimuli, but simple differences in single acoustic attributes did not appear to predict performance. For example, the dolphin discriminated two objects that produced echoes with very similar amplitudes. However, the number of highlights (amplitude peaks in the waveform) changed significantly when the stimuli rotated within a trial (Helweg, Au, Roitblat, \& Nachtigall, 1996). (See Figure 2 for waveforms of echoes from different aspects of a single

Waveforms of Echoes Collected from Three Different Angles of an Aspect-Dependent Object

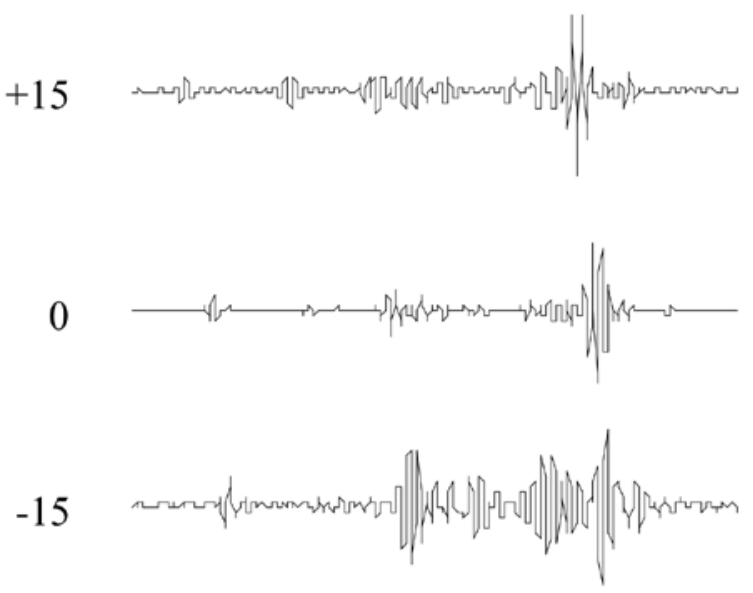

Figure 2. Comparison of waveforms (time on horizontal axis, amplitude on vertical axis) of echoes reflected from different angles of the same aspect-dependent object. 
object.) These changes in echoes across the echo train may have facilitated discrimination of the stimuli for the dolphin (Helweg, et al., 1996).

A dolphin can also identify objects when listening in on the echoes produced through the echolocation activity of a neighboring dolphin. In a 3-alternative matching-to-sample study a non-echolocating dolphin listened to the echoes returning from a sample object ensonified by an echolocating dolphin (the inspector) whose rostrum (the dolphin's socalled bottlenose) was within 5 degrees of the listening dolphin (Xitco \& Roitblat, 1996). Each dolphin then swam to its own 3-alternative array and was able to choose an object identical to the sample with above-chance accuracy when the objects were familiar to both dolphins. When objects were not familiar to both dolphins, the listener only chose correctly when the inspector chose correctly. Because the listener's errors were not predicted by the inspector's errors, choice accuracy was probably predicted by the quality of the returning echoes. That the listener was able to get enough information to identify an object is somewhat remarkable given the directionality of the dolphin echolocation system; echoes received $10^{\circ}$ off-axis can have a much lower intensity $(-10 \mathrm{~dB})$ with substantially lower frequencies $(-114 \mathrm{kHz}$ peak frequency) (Au, 1993) than on-axis echoes. That one dolphin can eavesdrop on another's echoes suggests that object constancy can be maintained even when echo quality is substantially reduced.

\section{Individual echoes or echo trains?}

As suggested earlier, dolphins probably use echo trains rather than individual echoes in order to discriminate among objects (DeLong, Au, Harley, et al., 2007; Roitblat et al., 1990, and Helweg et al., 1996). Results from neural network models using echoes as inputs suggest that dolphins integrate information across multiple echoes rather than depending on a single echo; classification is better when information is integrated across echoes (Moore, Roitblat, Penner, \& Nachtigall, 1991; Roitblat, Moore, Nachtigall, \& Penner, 1991).

Information in an echo train allows the use of changes in echoes as clicks reflect from different aspects of a target and produce substantively different echoes. Dolphins may be sensitive to changes in echoes across trains. For example, dolphins can use differences in amplitude occurring across multiple echoes (Dankiewicz, Helweg, Moore, \& Zafran, 2002). In a study in which the stimuli were echo trains carefully controlled to vary only in amplitude modulation (the stimuli were electronic echoes issued in response to the subject dolphin's emission of echolocation clicks), a dolphin discriminated between amplitude modulated (AM) echo trains and echo trains with no amplitude modulation. The threshold for discrimination was about $4.2 \%$ AM. However, because these were simulated echoes that were designed to vary in AM specifically, we do not know if an echolocating dolphin uses AM information for object recognition.

In another perception experiment a dolphin performed a go/no-go task in which she was rewarded for going when she heard echoes in noise and was rewarded for remaining at station when noise-only trials occurred (Altes, Dankiewicz, Moore, \& Helweg, 2003). A pre-determined number $(1,2,4,8$, or 16 echoes/test trial) of man-made echoes were returned, within noise, in response to the dolphin's echolocation clicks. Performance accuracy was very high for 16 echoes and decreased as the number of echoes decreased. Noise levels varied across trials; for 8 and 4 echoes, the signal-to-noise ratio had to be increased for detection, and it had to be increased even more in 1- and 2-echo trials. These results suggested that the dolphin was using multiple echoes for processing (Altes et al., 2003). Altes et al.'s models further suggested that the dolphin was integrating over each click-echo pair rather than waiting until all echoes were received. Multi-echo processing is necessary for detecting most object features because comparative information is required as echoes return from different parts of an object (Altes et al., 2003).

Analysis of echoes from objects linked to confusions made by a dolphin performing a matching-to-sample task also suggested use of echo trains for discrimination. An adult male dolphin discriminated among objects in 3-object sets in which object features varied in specific ways: shape, size, texture, material (DeLong et al., 2006). An analysis of performance accuracy, performance errors, features of echoes generated by the objects (target strength, number of highlights in the waveform, duration, peak frequency, center frequency, rms bandwidth), and features of echoes across changes in each object's orientation (relative target strength, relative number of highlights, changes in target strength, changes in waveform highlights) suggested that the dolphin neither used a single feature to discriminate among objects nor a linear combination of multiple features. Object features did not clearly predict echo features; e.g., size, shape, and material all interacted to affect echo intensity. In most sets, the dolphin could have used echoes and echo trains that varied in several ways: the distribution of energy across frequencies (i.e., echo spectrum shape), patterns of changes in target strength across object orientations, peak frequency, and center frequency.

\section{Extraction of object features through echolocation}

The results of the studies described in the previous sections 
provided information about the dolphin's ability to discriminate among echoes produced by objects in echoic detection, discrimination, and matching tasks. Some of the studies manipulated the stimuli in ways that required the dolphin to have an object-centered basis for organizing its echoes. For example, changes in object orientation led to very different echoes, but the dolphin maintained discrimination in some cases (e.g., Helweg et al., 1996). However, many of the tasks could have been solved by the dolphin's use of a sound matching solution. That is, the dolphin subjects could have been solely matching the echoes produced by the sample or standard to those of the echoes produced by a set of alternatives: Echo matching does not require object recognition; the dolphin could merely match the sounds produced by one object with the sounds produced by another. However, later experiments using cross-modal matching tasks required that dolphins use an object-based strategy for matching. In these tasks a dolphin matches across two modalities, i.e., vision and echolocation. When a sample is presented echoically and then a choice array is presented visually, the dolphin cannot merely match sounds because a visual display does not provide them. The dolphin must recognize some equivalence between its visual and echoic experiences of the objects to perform a cross-modal match with stimuli that are unfamiliar. In these studies the dolphin cannot have had previous simultaneous visual and echoic experiences with the stimuli because such experiences would have provided an opportunity for the dolphin to learn to associate an object's appearance and its echo in the same way that a person can learn to associate a rose's appearance with its odor.

Although the dolphin's visual sense has not been highlighted in this article, dolphins do see relatively well in air and underwater. In an experiment focused on visual acuity, an adult female dolphin viewed high-contrast black and white gratings in bright light both above and below the water's surface (Herman, Peacock, Yunker, \& Madsen, 1975). In water the best resolution was 8.2 arc minutes at 1 meter from the stimulus; in air it was 12.5 arc minutes at 2.5 meters from the stimulus. High illumination levels are probably necessary for good visual acuity in air because bright light causes the pupil to close in the middle to create two pinhole apertures for better focus. In contrast, in water the pupil remains open, and lower illumination levels should not have such a significant effect (Herman et al., 1975). In visual matching-to-sample tasks, dolphins have performed at high accuracy levels both with object stimuli (e.g., Herman, Hovancik, Gory, \& Bradshaw, 1989) and with two-dimensional forms (Hunter, 1988).

Pack, Herman, and their associates (Herman, Pack, \& Hoffmann-Kuhnt, 1998; Pack \& Herman, 1995; Pack, Herman, Hoffmann-Kuhnt, \& Branstetter, 2002) have conducted several cross-modal matching tasks with a sub-adult female dolphin, Elele. The dolphin was trained to match objects intra-modally (sample and choices both presented only visually or only echoically) and cross-modally (visual samples to echoic alternatives; echoic samples to visual alternatives). Tests were conducted with objects made of PVC pipes and fittings that usually had about the same amount of surface area and varied in shape. The sample object remained available during alternative choices. Objects accessible to vision only were presented in air; dolphin echolocation does not work in air due to the impedance mismatch between water and air. Objects accessible to echolocation only were presented behind a black Plexiglass panel and surrounded by slats of redwood that were intended to absorb or redirect sound. The dolphin matched well with most objects both intra-modally and cross-modally including first-trial presentations and when a trainer presented the objects via a television screen. When the dolphin did not have previous intra-modal experience with the objects, performance accuracy dropped. With four pairs of unfamiliar stimuli, cross-modal matching performance was above-chance with only two of the pairs. Performance accuracy improved as the dolphin gained more experience with the objects, potentially due to associative learning or to better representation of the objects' features. The experimenters evaluated some of the objects for overlapping object features as determined by the experimenters, e.g., diagonal piping, symmetry, closure, but the few confusions reported did not appear to be related to the features that the experimenters used to categorize the objects. The dolphin's performance accuracy with familiar objects remained at above-chance levels after the introduction of a paddle that indicated the correct choice alternative was not available; she used the paddle correctly when a matching object was indeed absent. The authors concluded that the dolphin had "perceived the objects holistically" and that "echolocation yields a direct percept of the object, in effect a representation of the object's shape" (Herman et al., 1998, p. 303). They called the process "echo imaging."

Work in another laboratory using a different method also suggested that dolphins recognize a correspondence between their visual and echoic experiences of object features (Harley, Putman, \& Roitblat, 2003). An adult male dolphin, Toby, performed a cross-modal (echoic samples to visual alternatives or visual samples to echoic alternatives) delayed matching-to-sample task with eighteen 3-object sets of randomly chosen unfamiliar junk objects. In most cases, the dolphin was reinforced for performing an identity match: after experiencing the sample object, he received fish for choosing an object identical to the sample from a 3-object array (Object A to Object A). However, with a pair of objects in each of six of the 3-object sets, the dolphin was rewarded for choosing an arbitrary, but consistent, alternative that was different from the sample (Object A to Object B). (See Figure 3 for 


\section{Object A}

\section{ז̊}

$\stackrel{\infty}{\ddot{\nu}}$
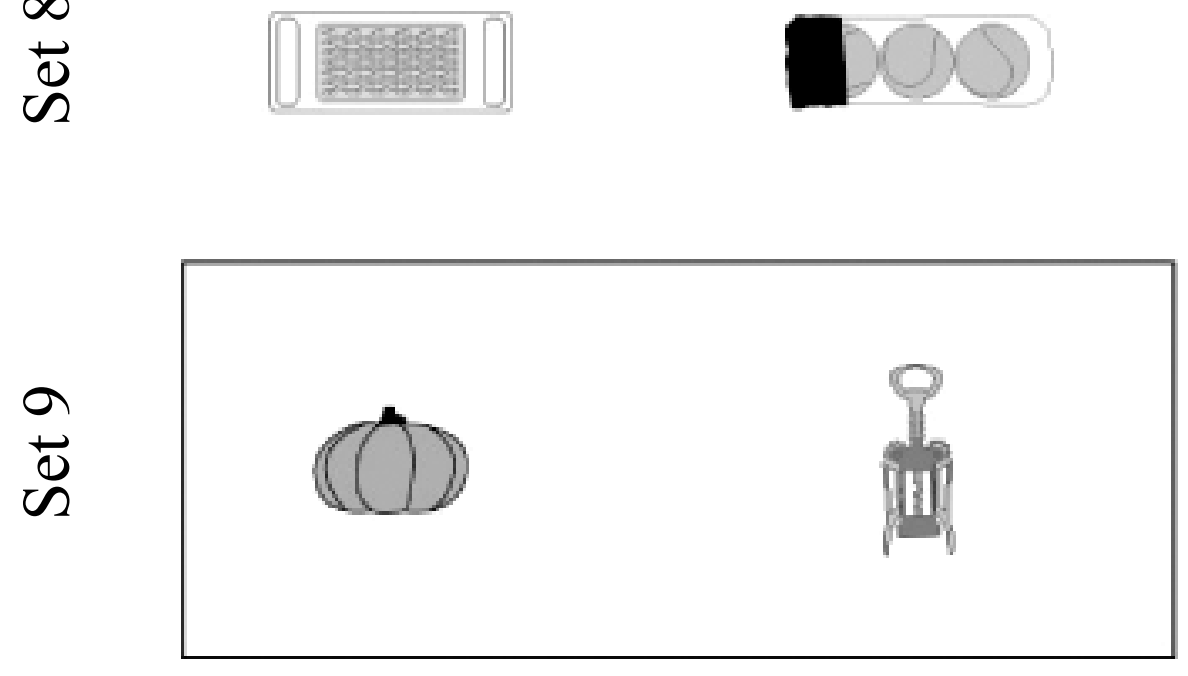

Object B
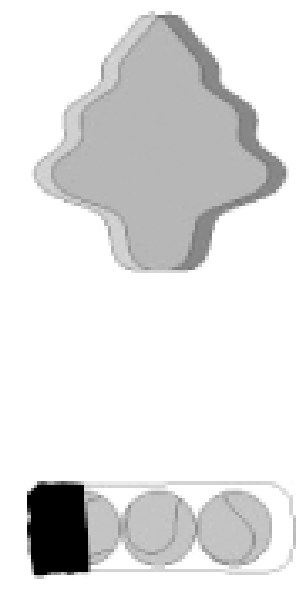

\section{Object C}

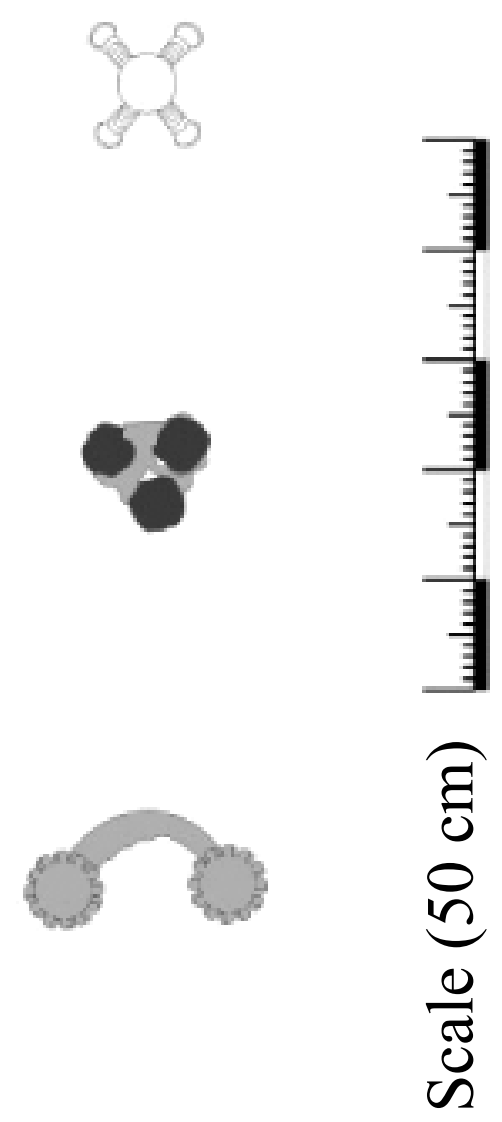

Figure 3. Examples of objects used as stimuli in Harley et al. (2003). In the experiment, objects were organized into 18 3-object sets. In cross-modal (visual sample to echoic choices or echoic samples to visual choices) conditions, the dolphin was reinforced for matching identical objects in most object sets, but in 6 of the 3-object sets, the dolphin was reinforced for associating different objects together. In the 3 object sets presented here, the dolphin was reinforced for matching identical objects for all objects except the boxed pair in Set 9; in that case the dolphin was reinforced for choosing the pumpkin after experiencing the corkscrew and for choosing the corkscrew after experiencing the pumpkin. From Bottlenose dolphins perceive object features through echolocation by H.E. Harley, E.A. Putnam, \& H.L. Roitblat, 2003, Nature, 424, Supplementry material.

examples of the stimuli.) If the dolphin was merely learning to associate his visual and echoic experiences, then he should have performed as well with the arbitrary matches as he did with the identity matches. However, if he recognized a correspondence between his visual and echoic experiences of the same object features, then his experience with identity matching should have led him to choose based on identity regardless of reinforcement contingencies. In the cross-modal conditions with the arbitrarily paired objects, the dolphin made 498/672 (74\%) identity-based choices versus 90/672 (13.4\%) rewarded choices. The dolphin chose the third alternative in the subset the remainder of the time. Three choices were always available, therefore, chance performance was $33 \%$. The stimuli were never presented simultaneously to the two modalities thereby allowing him to associate the two experiences, and reinforcement did not guide the dolphin's performance. The only method by which he could have associated his visual and echoic experiences of the same object was through the recognition that the object features experienced through the two different modalities were the same.

Dolphins integrate information received through vision and echolocation (Harley, Roitblat, \& Nachtigall, 1996). A young female dolphin, BJ, performed a 3-alternative delayed matching-to-sample task in which two objects were difficult to discriminate visually (both grey cylinders: the first PVC and striped, and the second steel and plain) and two objects were difficult to discriminate echoically (both 
PVC cylinders: the first white with varied thicknesses along its length, and the second grey and uniform along its length). Performance accuracy using vision or echolocation alone to perform the match was 70-77\%; when both vision and echolocation were used together, performance accuracy rose to 95\%. The dolphin also matched familiar objects across vision and echolocation, although performance accuracy was better from echoic samples to visual choices than from visual samples to echoic choices.

\section{Extracting object features from echo features: A difficult problem}

Immediate cross-modal matching with unfamiliar objects (Herman et al., 1998) and unreinforced identity matching across modalities (Harley et al., 2003) indicate that the dolphin extracts object feature information from echoes. However, we do not know which echo characteristics (e.g., frequency, amplitude) allow the dolphin to extract object feature information (e.g., size, shape) or how it works. In terms of object recognition, this puzzle is the most pressing and interesting problem for scientists working in this area.

In echoes, dolphins can discriminate among small differences in intensity, frequency, and time, and they appear to use all of these options when discriminating among echoes produced by different objects. Humans also use all of these differences for discrimination and recognition. However, even the simplest shapes produce highly complex echoes that are highly variable depending upon physical conditions and the angle at which a click reflects from an object. Features interact to confound each other such that similar features produce different echoes. For example, in Helweg et al.'s (1996) study, the planar faces of the rectangular prism and the cube had the same surface area in an expectation that they would produce echoes with similar amplitudes. However, in practice they had different echo amplitude distributions (Helweg et al., 1996).

Intuitively, one might expect that echolocation could produce an image-like representation easily available to visual processes, but, to date, the evidence for this kind of representation is scant. Unlike a medical ultrasound apparatus which produces sounds at very high frequencies and repetitions and stores echoic information in parallel on a CRT display, dolphin echoes are relatively low in number, serial, and stored in memory (Roitblat, Helweg, \& Harley, 1995). Similarly, echolocation does not work like vision which processes high-speed light of relatively tiny wavelengths in parallel. Dolphins may receive about 50 echoes per second. Roitblat et al. (1995) used neural and psychophysical information about the dolphin's visual and auditory systems to estimate the number of bits per second available to the dolphin visu- ally and echoically. These broad estimates suggested that the dolphin eye can transmit about 31 bits per second and the echolocation system can transmit about 20 bits per second.

Theoretically, the dolphin could integrate information across echoes to create a spatial-analog representation (Altes, 2004). Under substantial constraints, some models have been successful at producing information from echoes that could be interpreted in terms of object features (Gaunaurd, Brill, Huang, Moore, \& Strifors, 1998). Therefore, dolphins may be able to represent echoically perceived objects in an image-like way. Of course, acoustic images are not required to have a visually image-like flavor (Roitblat, 2002). Acoustic images may be quite different from visual images, but both could augment each other to provide the hierarchically organized object-focused representation dolphins appear to use (Harley et al., 1996). For example, imagine that you are feeling (but not seeing) an unfamiliar transparent juice glass with a complex raised pattern on its exterior. You can feel the opening at the top of the glass and the solid bottom; you may have a general sense of the glass's structure without a clear representation of the raised pattern. However, once you put the glass down and see the raised pattern (even without feeling it), you note that the pattern you were feeling is a bunch of cherries hanging down from leafy stems. The next time you feel those cherries, you will be able to access your visual representation of the cherry pattern. At that point, your tactile experience of the cherries, stems, and leaves will likely be clear and specific. The knowledge you gained visually has informed your tactile perception. Because dolphins can use information gained through different sensory systems concerning a single object to produce an object-focused representation (Harley et al., 1996), the dolphin likely uses information received from different modalities to inform its future single-modality investigations of a previously represented object.

Herman, Pack, and colleagues (1995, 1998, 2002) suggest that the dolphin can extract a holistic representation of an object's shape from the echoes. However, the dolphins in cross-modal studies may have targeted more specific aspects of the objects to perform the cross-modal matches. For example, information about a specific angle or overall target strength information based on how much material was present in one area of an object versus another may have allowed for good immediate matching performance given the constraints that two or three alternatives provide. [Although Herman and Pack took pains to control for overall surface area among their stimulus sets, amplitudes can still vary substantially even so (e.g., Helweg et al., 1996).] After a single successful cross-modal matching trial the dolphin could use its visual experience of an object to inform its future investigations of that object. That Herman et al. (1998) found significantly worse cross-modal matching with objects that 
had not been previously investigated intra-modally suggests that experience has an effect.

It is possible that dolphins extract holistic shape information from objects using echolocation, but it is also possible that they blend information provided through vision and echolocation to build the details of their representation of an object's shape. Vision usually allows perception of an entire object (at least its face) all at once, and thus a holistic representation is readily available. On the other hand, echolocation likely provides much more pointed information about pieces of objects that are salient through sound rather than providing an analog to a picture like a manmade ultrasound scanner. The dolphin's echolocation beam pattern is a narrow 10 degrees, and many parts of an echolocated object, including some internal surfaces, reflect. Building a holistic representation based solely on echoic information would be very difficult. Blending visual and echoic information, something that dolphins do, would result in a rich representation of overall shape and internal structure.

Experiments that might provide evidence of object shape extraction from echoes alone include echoic studies in which objects maintain their shape but vary in overall size or material. In this case, the objects and their echoes will change, but shape will remain the same. An analysis of the echoes and confusions in such experiments might provide insights into what the dolphin uses in the echoes in order to identify shape or parts of a shape. In another kind of experiment with a similar goal, the dolphin might learn to identify specific object features and indicate their presence or absence when stimuli were presented visually and/or echoically (Kastak, personal communication). In any case, more investigations of shape as it varies need to be conducted in order to assert that dolphins perceive shape globally using echolocation.

More acoustic analyses of echoes from objects used in cross-modal studies may also provide useful information. Because the dolphin does extract some object feature information that is available to both vision and echolocation, the echoes from cross-modal stimuli have clearly encoded that information. Analyzing those echoes when a dolphin can and cannot match well across vision and echolocation may offer some insight into what the dolphin is using in the echoes. In the next section we present some previously unpublished data including acoustic analyses of objects used by the dolphin Toby when he was performing the 3-alternative cross-modal matching task described in Harley et al. (2003). We analyzed echoes from several sets of objects in which the dolphin's performance accuracy varied in order to learn more about which echo features might be translated into object features.

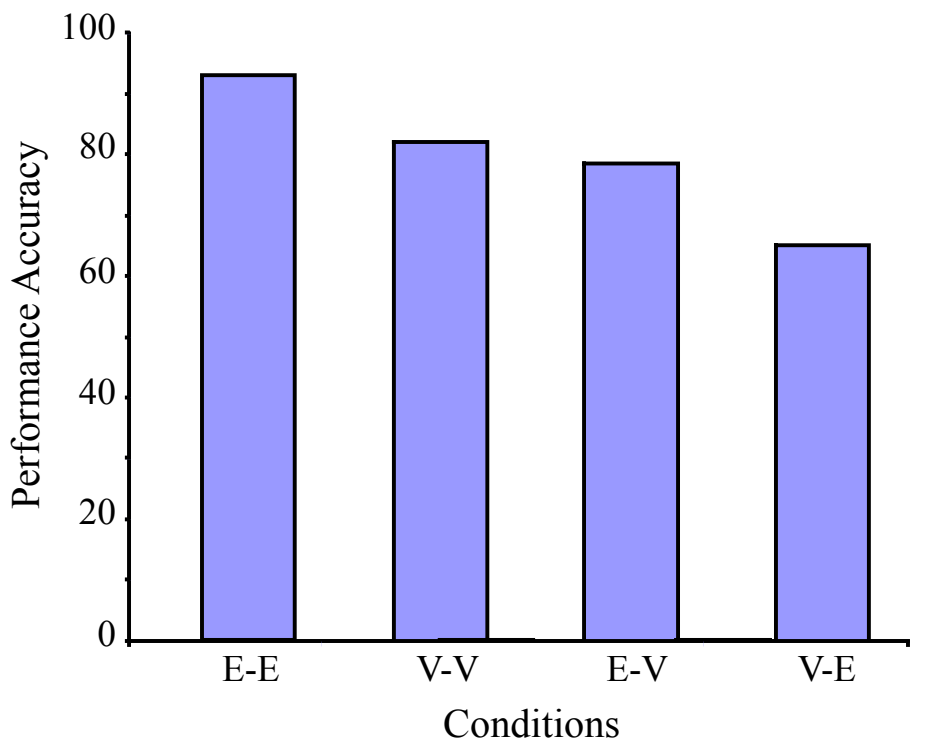

Figure 4. Mean performance accuracy in each condition with all 18 3-object sets. Object sets were always introduced in cross-modal conditions before intramodal conditions. Each set was presented for two 18-trial sessions except during its original introduction in one cross-modal condition. In this case, half of the object sets were introduced in the $E-V$ condition for 8-10 sessions and half of the object sets were introduced in the V-E condition for 8-10 sessions.

\section{Experimental report: Acoustic analyses of stimuli from a cross-modal task}

The adult male dolphin, Toby, performed a 3-alternative object matching task in which objects were presented in cross-modal sessions (visual sample to echoic alternatives, echoic sample to visual alternatives) after which they were presented in intra-modal sessions (visual sample to visual alternatives, echoic sample to echoic alternatives). For more details about the behavioral method, see Harley et al. (2003). The objects from some sets were subsequently measured acoustically by echolocating them with a frequently used man-made dolphin click (see Au, 1993) that was $70 \mu$ s long with a peak frequency of about $120 \mathrm{kHz}$ and a $60-\mathrm{kHz}$ bandwidth. Echoes were measured from multiple angles parallel to the horizontal axis of the center of the target between -15 degrees and +15 degrees off center. Six standard acoustic features were extracted from each individual echo: (1) target strength, (2) number of highlights, (3) duration, (4) peak frequency, (5) center frequency, and (6) root-mean-square (rms) bandwidth. For details about the echo measurement set-up and procedure, see DeLong et al., 2006..

Performance accuracy across conditions. The dolphin's performance accuracy varied across object sets and condi- 


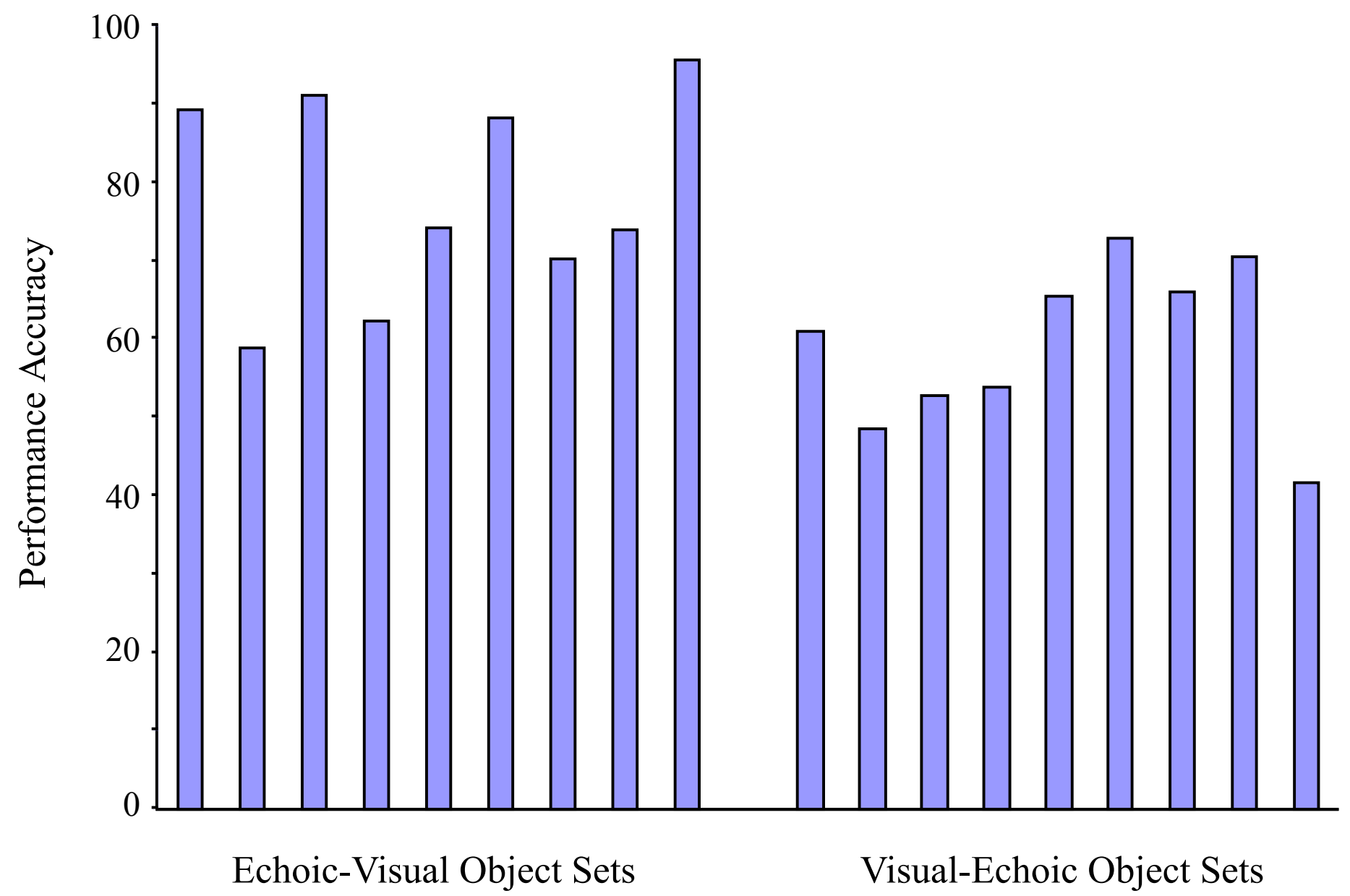

Figure 5. Mean performance accuracy across 8-10 18-trial sessions with 18 different object sets presented either with an echoic sample to a 3-alternative visual alternative array or with a visual sample to a 3-alternative echoic array.

tions from the worst performance with one set in the V-E condition at $41.6 \%$ accuracy to the best performance with another object set in the E-V condition at $95.6 \%$ accuracy. See Figure 4 for mean performance accuracy across conditions and Figure 5 for mean performance accuracy across cross-modal conditions by object set. Mean performance accuracy across the sets was best in the intra-modal conditions: $\mathrm{E}-\mathrm{E}=93.44 \%$ and $\mathrm{V}-\mathrm{V}=82.28 \%$. There was an asymmetry in cross-modal performance depending on the condition. Mean performance accuracy across sets in the E-V condition (78.67\%) was better than in the V-E condition $(65.39 \%)$. This asymmetry also occurred in a similar task with a female sub-adult dolphin working in Kaneohe Bay: With three familiar 3-object sets, performance was better in the E-V condition $(72 \%, 100 \%, 67 \%)$ than the V-E condition (22\%, 61\%, 39\%, respectively) (Harley et al., 1996).

Asymmetries across different conditions in cross-modal tasks are common (e.g., Rose \& Orlian, 1991) and likely occur (when intra-modal matching is strong) because features salient in one modality are less salient or not available in another. For example, differences in the material from which an object is made may be easier to detect using touch or echolocation than using sight. However, Pack, Herman, and colleagues $(1995,1998,2002)$ did not find any asymmetries in cross-modal studies with their dolphin. The reason for the dissimilar findings across studies is not clear. The most obvious difference among the studies is that the echoic stimuli investigated by Pack and Herman's dolphin were presented inside a slatted, redwood box. In both of the Harley studies, the echoic objects were presented in more open water without an immediate, solid background. Harley's stimuli also varied on a variety of features - material, shape, size, texture. Pack and Herman's stimuli were always large shapes made out of a variety of PVC sizes and types. In future cross-modal studies, analysis of asymmetries occurring with stimuli varying on specific dimensions could help determine features that are and are not available across vision and echolocation.

Narrow vs. wide acoustic measurements. Three of the 18 three-object sets from the cross-modal matching study (Harley et al., 2003) were chosen for acoustic analysis based on the dolphin's performance with them in the four differ- 
Table 1. Dolphin's Performance Accuracy on Each Object Set Analyzed Acoustically

\begin{tabular}{cllcccc}
\hline & & \multicolumn{4}{c}{ Dolphin's Performance Accuracy } \\
\cline { 2 - 6 } Set & Objects & E-E & V-V & E-V & V-E & Type \\
\hline 1 & $\begin{array}{l}\text { Elephant } \\
\text { Tin Cup } \\
\text { Foam Cones }\end{array}$ & $89 \%$ & $92 \%$ & $89 \%$ & $95 \%$ & All Good \\
\hline 2 & $\begin{array}{l}\text { Helmet } \\
\text { Horn } \\
\text { Plunger }\end{array}$ & $67 \%$ & $89 \%$ & $67 \%$ & $61 \%$ & Echoic Problem \\
\hline 3 & $\begin{array}{l}\text { Baby Bottle } \\
\text { Tree Pan } \\
\text { Wood Massager }\end{array}$ & $97 \%$ & $100 \%$ & $62 \%$ & $39 \%$ & Cross-modal \\
Problem
\end{tabular}

Table 2. Dolphin's Errors (Object Confusions) in Each Condition

\begin{tabular}{|c|c|c|c|c|c|}
\hline \multirow[b]{2}{*}{ Set } & \multirow[b]{2}{*}{ Objects } & \multicolumn{4}{|c|}{ Condition/Confusion } \\
\hline & & E-E & $\mathrm{V}-\mathrm{V}$ & E-V & V-E \\
\hline 1 & $\begin{array}{l}\text { Elephant } \\
\text { Tin Cup } \\
\text { Foam Cones }\end{array}$ & $\begin{array}{c}\text { Ele-Cones } \\
\mathbf{5 / 5}\end{array}$ & $\begin{array}{c}\text { Ele-Cup } \\
\mathbf{3 / 5} \\
\text { Ele-Cones } \\
2 / 5 \\
\end{array}$ & $\begin{array}{c}\text { Ele-Cup } \\
12 / 17 \\
\text { Ele-Cones } \\
5 / 17 \\
\end{array}$ & $\begin{array}{c}\text { Ele-Cup } \\
2 / 2\end{array}$ \\
\hline 2 & $\begin{array}{l}\text { Helmet } \\
\text { Horn } \\
\text { Plunger }\end{array}$ & $\begin{array}{c}\text { Horn-Plng } \\
\mathbf{1 0} / \mathbf{1 2} \\
\text { Helm-Plng } \\
2 / 12\end{array}$ & $\begin{array}{c}\text { Horn-Plng } \\
4 / 4\end{array}$ & $\begin{array}{c}\text { Horn-PIng } \\
12 / 12\end{array}$ & $\begin{array}{c}\text { Horn-Plng } \\
\text { 29/59 } \\
\text { Helm-Plng } \\
22 / 59 \\
\text { Helm-Horn } \\
8 / 59\end{array}$ \\
\hline 3 & $\begin{array}{l}\text { Baby Bottle } \\
\text { Tree Pan } \\
\text { Wood Massager }\end{array}$ & $\begin{array}{c}\text { Tree-Wood } \\
1 / 1\end{array}$ & No errors & $\begin{array}{c}\text { Tree-Wood } \\
\mathbf{5 9 / 6 8} \\
\text { Baby-Tree } \\
8 / 68 \\
\text { Baby-Wood } \\
1 / 68\end{array}$ & $\begin{array}{c}\text { Baby-Tree } \\
\text { 9/19 } \\
\text { Baby-Wood } \\
\text { 6/19 } \\
\text { Tree-Wood } \\
\text { 4/19 }\end{array}$ \\
\hline
\end{tabular}

Note. $E$-E = Echoic sample, echoic choices; $V$-V = visual sample, visual choices; $E$-V = Echoic sample, visual choices; V-E $=$ visual sample, echoic choices. The number of errors in the confusion category out of the total number of errors is shown in each cell under the error type. The predominant confusion (accounting for the majority of the errors) is shown in bold. There were two 18-trial sessions in each condition except that odd-numbered object sets included 8-10 18-trial E-V sessions (the first condition with those objects) and even-numbered object sets contained 8-10 18-trial V-E sessions (the first condition with those objects). 
Table 3. Acoustic Feature Measurements for Each Object Around the $0^{\circ}$ Orientation

\begin{tabular}{clcccccc}
\hline & & \multicolumn{5}{c}{ Acoustic Feature } \\
\cline { 3 - 7 } Set & Objects & TS & HL & PkFr & CtFr & BW & Dur \\
\hline \multirow{2}{*}{1} & Elephant & $-46.7(1.6)^{\mathrm{a}}$ & $9.8(3.5)^{\mathrm{a}}$ & $118.1(3.4)^{\mathrm{a}}$ & $114.9(1.6)^{\mathrm{a}}$ & $21.2(1.7)^{\mathrm{a}}$ & $740.4(101.2)^{\mathrm{a}}$ \\
& Tin Cup & $-24.3(0.9)^{\mathrm{b}}$ & $3.1(0.3)^{\mathrm{b}}$ & $119.4(4.9)^{\mathrm{a}}$ & $118.0(0.9)^{\mathrm{b}}$ & $14.4(0.1)^{\mathrm{b}}$ & $277.0(23.3)^{\mathrm{b}}$ \\
& Foam Cones & $-28.6(1.9)^{\mathrm{c}}$ & $1.4(0.5)^{\mathrm{c}}$ & $114.6(4.9)^{\mathrm{b}}$ & $114.4(5.4)^{\mathrm{a}}$ & $13.7(1.6)^{\mathrm{b}}$ & $65.1(8.6)^{\mathrm{c}}$ \\
\hline \multirow{2}{*}{2} & Helmet & $-36.9(1.3)^{\mathrm{a}}$ & $4.0(0.9)^{\mathrm{a}}$ & $115.1(3.3)^{\mathrm{a}}$ & $119.3(0.8)^{\mathrm{a}}$ & $14.4(1.3)^{\mathrm{a}}$ & $190.8(46.2)^{\mathrm{a}}$ \\
& Horn & $-31.7(0.5)^{\mathrm{b}}$ & $2.0(0.0)^{\mathrm{b}}$ & $109.2(1.7)^{\mathrm{b}}$ & $116.7(0.9)^{\mathrm{b}}$ & $13.5(0.4)^{\mathrm{b}}$ & $69.5(1.5)^{\mathrm{b}}$ \\
& Plunger & $-29.4(4.6)^{\mathrm{c}}$ & $1.8(1.1)^{\mathrm{b}}$ & $119.5(8.5)^{\mathrm{c}}$ & $114.7(3.6)^{\mathrm{c}}$ & $18.9(3.5)^{\mathrm{c}}$ & $54.1(26.1)^{\mathrm{c}}$ \\
\hline \multirow{2}{*}{3} & Baby Bottle & $-31.0(3.7)^{\mathrm{a}}$ & $2.3(0.8)^{\mathrm{a}}$ & $112.3(6.9)^{\mathrm{a}}$ & $114.0(6.6)^{\mathrm{a}}$ & $13.3(2.1)^{\mathrm{a}}$ & $83.7(14.4)^{\mathrm{a}}$ \\
& Tree Pan & $-27.9(1.4)^{\mathrm{b}}$ & $4.8(1.2)^{\mathrm{b}}$ & $122.3(4.6)^{\mathrm{b}}$ & $122.8(4.0)^{\mathrm{b}}$ & $15.5(1.7)^{\mathrm{b}}$ & $138.8(14.2)^{\mathrm{b}}$ \\
& Wood Massager & $-46.2(2.1)^{\mathrm{c}}$ & $3.7(1.1)^{\mathrm{c}}$ & $116.2(6.5)^{\mathrm{a}}$ & $111.3(3.3)^{\mathrm{a}}$ & $16.6(1.6)^{\mathrm{b}}$ & $127.7(42.8)^{\mathrm{b}}$ \\
\hline
\end{tabular}

Note. For each object, the value for each acoustic feature is shown averaged across ten echo measurements, in which each measurement included three echoes spanning $3^{\circ}$ (30 echoes). The standard deviation is given in parentheses following the mean. Statistically significant differences between means are indicated by different lower case letters. TS = target strength $(d B), H L=$ number of highlights, $P k F r=$ Peak frequency $(\mathrm{kHz}), C t F r=$ Center Frequency $(k H z), B W=r m s$ Bandwidth $(\mathrm{kHz})$, Dur = Duration $(\mu \mathrm{sec}$.)

ent modality conditions. Figure 6 portrays the objects (junk objects chosen to be maximally discriminable visually and echoically). Table 1 shows the dolphin's performance across all conditions (Echoic sample-Echoic alternatives: E-E, Visual sample-Visual alternatives: V-V, Echoic sample-Visual alternatives: E-V, and Visual sample-Echoic alternatives: VE) for the three object sets. The dolphin performed well in all conditions for object set 1 . For object set 2, the dolphin performed well in the $\mathrm{V}-\mathrm{V}$ condition but poorly in all other conditions involving echolocation (E-E, E-V, V-E). For object set 3 , the dolphin performed well in both intra-modal conditions but poorly in both cross-modal conditions.

Measurements of acoustic features are shown in two tables to examine how the features change with a narrow (Table 2: $0^{\circ}+/-3^{\circ}$ ) versus wide (Table 3: $0^{\circ}+/-15^{\circ}$ ) range of object orientations $\left(0^{\circ}\right.$ is face on). The mean values for each acous-

Table 4. Acoustic Feature Measurements for Each Object Spanning Multiple Orientations $\left(+/-15^{\circ}: 23\right.$ echoes per object)

\begin{tabular}{clcccccc}
\hline & & \multicolumn{5}{c}{ Acoustic Feature } \\
\cline { 2 - 7 } Set & Objects & TS & HL & PkFr & CtFr & BW & Dur \\
\hline \multirow{2}{*}{1} & Elephant & $-50.9(2.8)^{\mathrm{a}}$ & $15.6(5.8)^{\mathrm{a}}$ & $110.7(7.5)^{\mathrm{a}}$ & $110.3(3.1)^{\mathrm{a}}$ & $22.9(2.7)^{\mathrm{a}}$ & $809.9(65.7)^{\mathrm{a}}$ \\
& Tin Cup & $-36.6(6.0)^{\mathrm{b}}$ & $7.2(2.5)^{\mathrm{b}}$ & $115.0(7.0)^{\mathrm{b}}$ & $115.3(2.4)^{\mathrm{b}}$ & $15.7(1.9)^{\mathrm{b}}$ & $425.6(115.3)^{\mathrm{b}}$ \\
& Foam Cones & $-36.9(6.8)^{\mathrm{b}}$ & $3.7(2.1)^{\mathrm{c}}$ & $113.3(9.3)^{\mathrm{b}}$ & $114.0(4.8)^{\mathrm{c}}$ & $15.5(3.0)^{\mathrm{b}}$ & $271.2(253.2)^{\mathrm{c}}$ \\
\hline \multirow{2}{*}{2} & Helmet & $-40.3(3.4)^{\mathrm{a}}$ & $5.9(1.7)^{\mathrm{a}}$ & $116.2(10.0)^{\mathrm{a}}$ & $119.8(5.0)^{\mathrm{a}}$ & $15.7(2.4)^{\mathrm{a}}$ & $199.3(49.7)^{\mathrm{a}}$ \\
& Horn & $-36.1(3.4)^{\mathrm{b}}$ & $2.7(0.9)^{\mathrm{b}}$ & $114.0(6.8)^{\mathrm{b}}$ & $115.7(3.3)^{\mathrm{b}}$ & $15.4(2.0)^{\mathrm{a}}$ & $83.6(13.4)^{\mathrm{b}}$ \\
& Plunger & $-35.1(4.6)^{\mathrm{c}}$ & $2.4(0.8)^{\mathrm{c}}$ & $114.4(8.6)^{\mathrm{ab}}$ & $112.8(4.9)^{\mathrm{c}}$ & $15.9(3.3)^{\mathrm{a}}$ & $84.3(29.6)^{\mathrm{b}}$ \\
\hline \multirow{2}{*}{3} & Baby Bottle & $-32.8(3.0)^{\mathrm{a}}$ & $2.8(1.0)^{\mathrm{a}}$ & $116.3(9.3)^{\mathrm{a}}$ & $114.2(5.2)^{\mathrm{a}}$ & $15.2(2.9)^{\mathrm{a}}$ & $89.6(17.6)^{\mathrm{a}}$ \\
& Wood Massager & $-46.4(2.2)^{\mathrm{b}}$ & $4.7(1.4)^{\mathrm{b}}$ & $111.3(10.3)^{\mathrm{b}}$ & $110.6(3.9)^{\mathrm{b}}$ & $17.5(2.5)^{\mathrm{b}}$ & $182.9(128.1)^{\mathrm{b}}$ \\
& Tree Pan & $-31.9(4.1)^{\mathrm{c}}$ & $5.5(1.3)^{\mathrm{c}}$ & $116.6(7.6)^{\mathrm{a}}$ & $118.2(4.8)^{\mathrm{c}}$ & $15.7(2.2)^{\mathrm{a}}$ & $204.8(116.1)^{\mathrm{b}}$ \\
\hline
\end{tabular}

Note. For each object, the value for each acoustic feature is shown averaged across ten echo measurements, in which each measurement included 23 echoes spanning $30^{\circ}$ (230 echoes). The standard deviation is given in parentheses following the mean. Statistically significant differences between means are indicated by different lower case letters. TS $=$ target strength $(d B), H L=$ number of highlights, $P k F r=$ Peak frequency $(k H z), C t F r=$ Center Frequency $(\mathrm{kHz}), B W=r m s$ Bandwidth $(\mathrm{kHz})$, Dur $=$ Duration $(\mu \mathrm{sec}$. 
tic feature change depending on the range of orientations examined. For example, in Set 1 the mean target strength of the tin cup around $0^{\circ}$ is $-24.3 \mathrm{~dB}$ whereas the mean target strength for the same object averaged across $30^{\circ}$ is $-36.6 \mathrm{~dB}$. In addition, the standard deviations for the features are typi- cally higher for the objects measured over a wide orientation range compared to the narrow range. Whether the dolphin sampled a narrow or wide range of orientations during the task is not known, but these acoustic feature measurements show that we must determine how a dolphin investigated

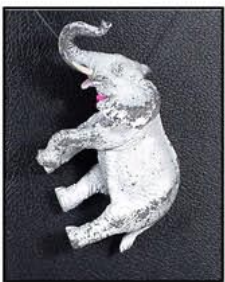

Elephant

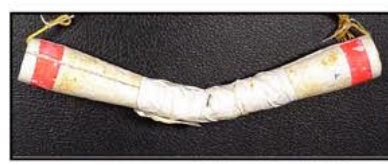

Foam Cones

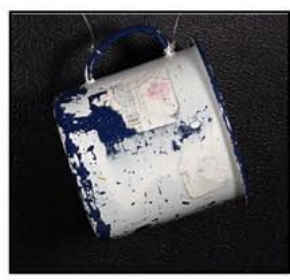

Tin Cup

\section{Set 1}

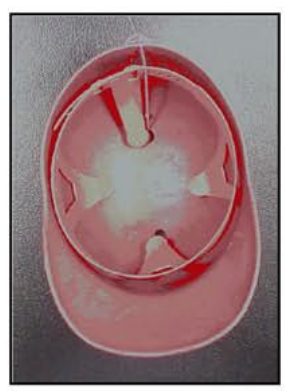

Helmet

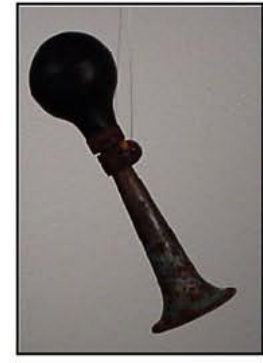

Horn

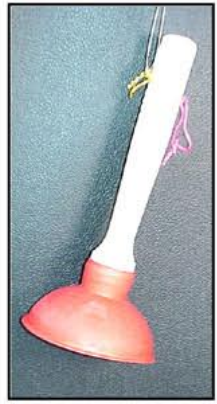

Plunger

\section{Set 2}

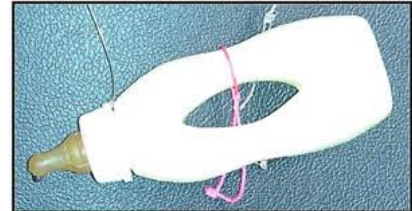

Baby Bottle

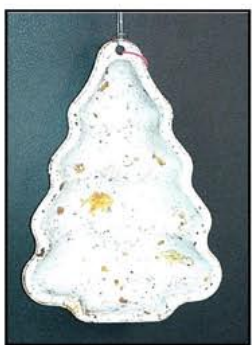

Tree Pan

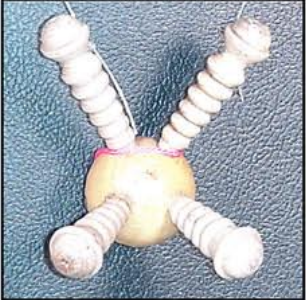

Wood Massager

\section{Set 3}

Figure 6. Object sets analyzed acoustically. 

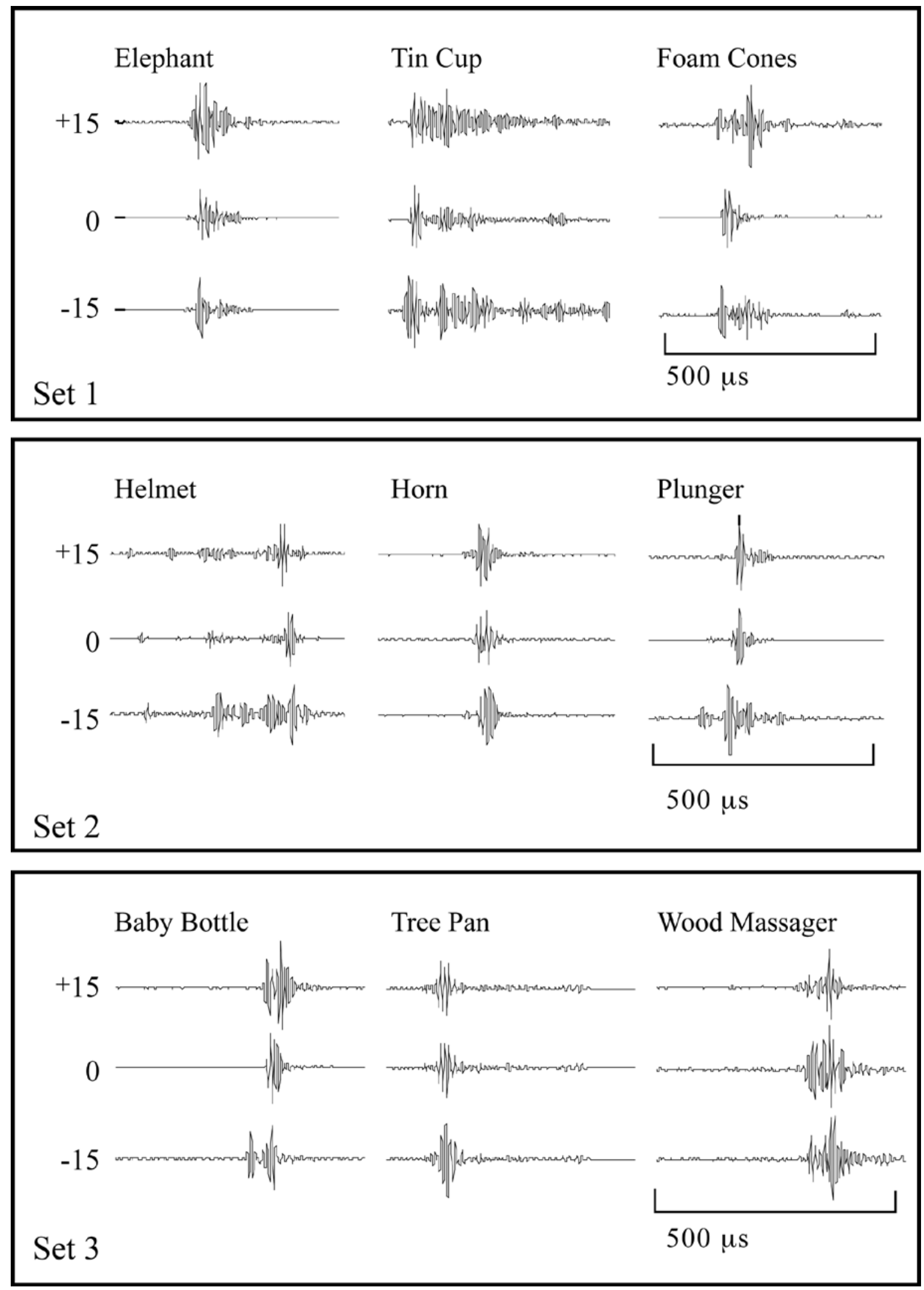

Figure 7. Echo waveforms (time vs. amplitude plots) showing changes in echo highlight structure as a function of object orientation $\left(-15^{\circ}, 0^{\circ}\right.$, and $\left.+15^{\circ}\right)$ for each object in the three object sets. 
objects during an echolocation task (particularly for aspectdependent objects) to know what acoustic information was available in echoes. A better method would be to record the actual clicks and echoes in relation to object orientation during the task to provide the most accurate determination of the dolphin's information. Recent work by Houser et al. (2005) showcases an excellent device to record clicks and echoes by a working dolphin.

Object confusions. The dolphin's object confusions (presented in Table 4) were analyzed in conjunction with the acoustic features of the object echoes (presented in Tables 2 and 3 ) to determine which features the dolphin could have used to discriminate among the objects. In Table 4 the predominant error, the object confusion that accounts for the majority of the dolphin's errors, is shown in bold.

To examine between-object differences in the acoustic features, separate multivariate analyses of variance (MANOVAs) were conducted for each of the three object sets. Between-object differences were examined within object sets because the dolphin matched objects within sets but not between sets. In the MANOVAs, the independent variables were object and orientation and the dependent variables were the six acoustic features: target strength, number of highlights, peak frequency, center frequency, rms bandwidth, and duration. In both the narrow and wide range of orientations, there were significant multivariate effects of object, orientation, and object $\mathrm{x}$ orientation for all object sets (for all tests, $\mathrm{p}<0.01$ ). For all object sets, there were significant differences among objects for all six acoustic features (for all features in all sets, $\mathrm{p}<0.01$ ). Post-hoc object comparisons were conducted for both sets of MANOVAs to examine which pairs of objects within each set showed significant differences in these acoustic features. Statistically significant differences between means are indicated by different lower case letters in Tables 2 and 3. (Different letters mean objects are statistically different on the measures; objects followed by the same letters are similar, i.e., not significantly different.)

To examine which acoustic features the dolphin may have used to discriminate among the objects, the pattern of errors made by the dolphin was considered in conjunction with the results of the post-hoc object comparisons. If two objects in a set had similar values for a certain acoustic feature (i.e., they were not significantly different on that feature, and they shared the same lower case letter in the Tables), and the dolphin made errors between those two objects, then it was inferred that those acoustic features may have been part of the dolphin's decision-making process and used by the dolphin to construct representations of the objects. In addition, echo trains were considered. All the objects analyzed acoustically had highly aspect-dependent echoes, i.e., the acoustic fea-
Set 1

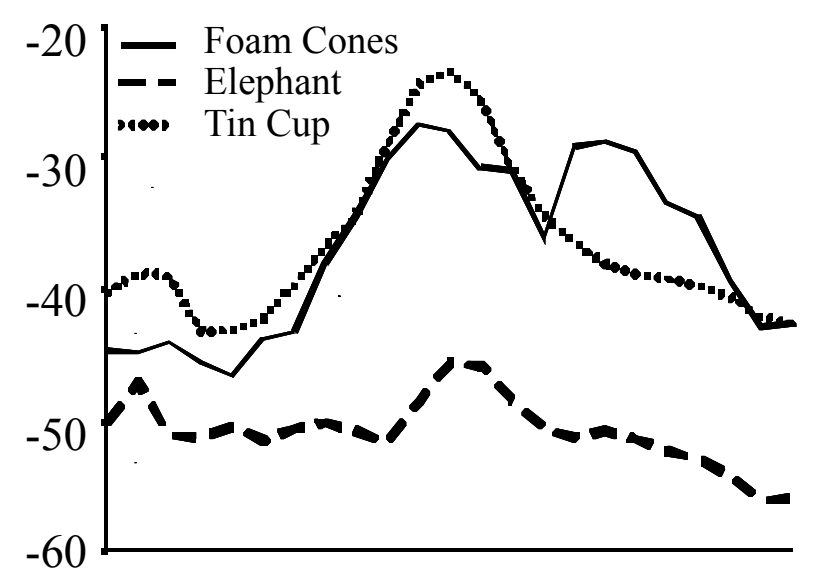

Set 2
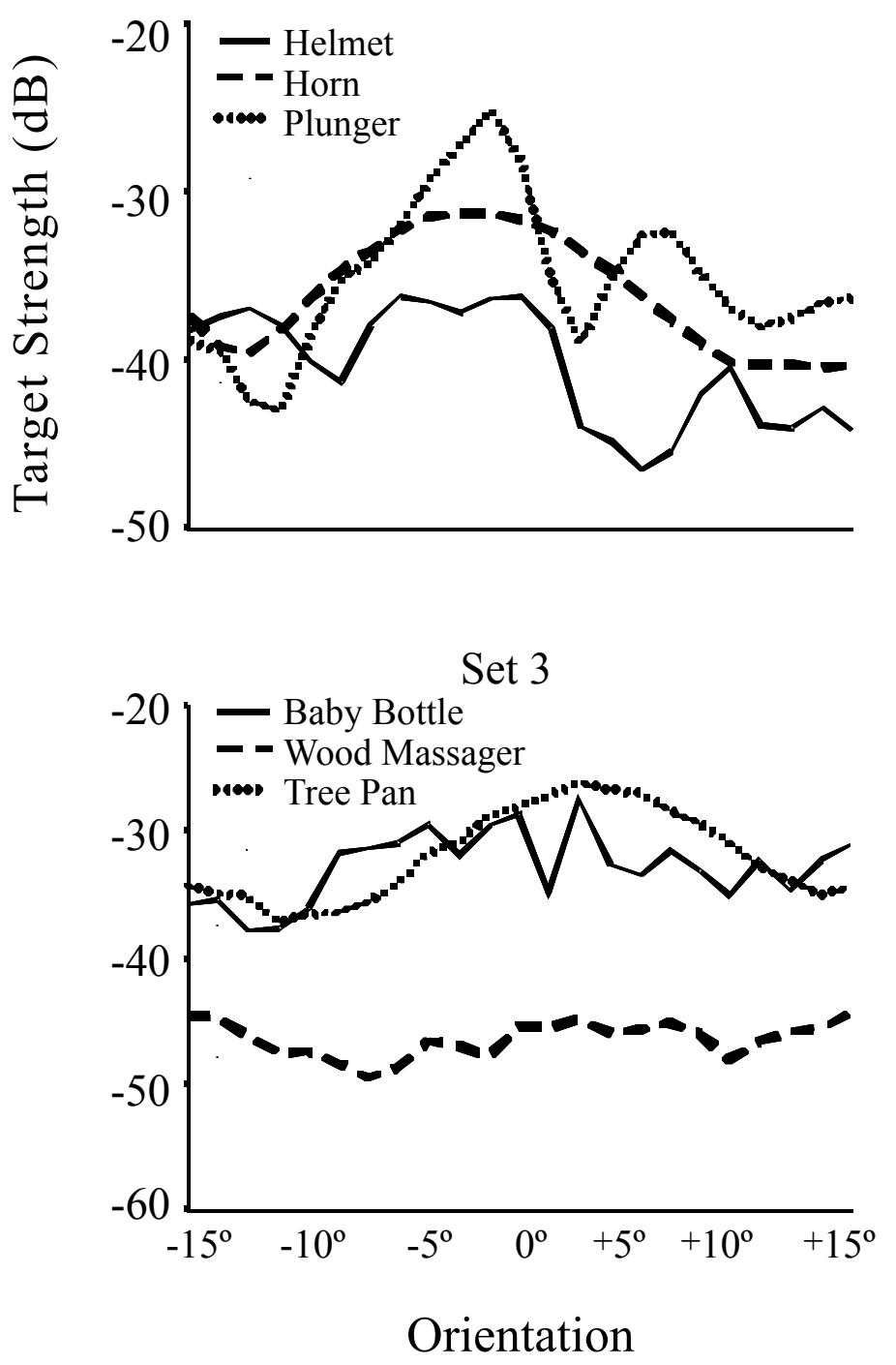

Figure 8. Plots showing changes in target strength as a function of object orientation for each object in the three object sets. 
tures of the objects changed as a function of orientation. Figures 7 and 8 show the highlight structure and target strength (respectively) of the objects changed as a function of orientation (the other acoustic features peak frequency, center frequency, bandwidth, and duration also changed but are not pictured). That the acoustic features of objects can vary so much with orientation creates a potentially salient feature: the pattern of changes in the echo across several orientations of the object.

Object Set 1: Elephant, Foam Cones, Tin Cup. Predominant confusions always involved the elephant. In the E-E condition, the dolphin always confused the elephant with the foam cones even though the foam cones and tin cup were most similar on most acoustic measures (e.g., target strength, peak frequency, bandwidth). However, the tin cup had the most distinctive highlight structure (as presented in the echo waveforms in Figure 7) compared to the other stimuli; it is possible that the dolphin used highlight structure as a cue, perhaps detected as TSP as suggested in previous echoic dolphin studies (e.g., Au \& Pawloski, 1989). Visually, the tin cup and elephant were most often confused; this confusion may have been due to similar surface area (see Figure 6 for objects).

Object Set 2: Helmet, Horn, Plunger. The predominant confusion in all conditions was between the horn and the plunger. The objects were similarly shaped, and the third object, helmet, was most distinctive on most acoustic measures. In addition, the helmet's highlight structure (Figure 7) was most distinctive.

Object Set 3: Baby Bottle, Tree Pan, Wood Massager. All but one confusion in this object set occurred in the crossmodal conditions; the dolphin only missed one trial in the intra-modal sessions. This lack of intra-modal errors suggested that the objects were easy to discriminate echoically and visually, however, this distinctiveness did not translate into good cross-modal performance. Apparently, the features that were salient in one modality did not translate easily into the other. In the Echoic-Visual condition, 59/68 errors $(86 \%)$ occurred between the tree pan and the wood massager. In the Visual-Echoic condition, 9/19 (47\%) of the confusions were between the baby bottle and the tree pan. Although tree pan and wood massager were somewhat similar on a few acoustic measurements (bandwidth, duration), they were fairly different on most. Baby bottle and tree pan had similarities in target strength, peak frequency, and bandwidth (wide range of orientations). The objects did not clearly differ in highlight structure which may have affected performance. The wood massager had the weakest target strength.

Target strength. Simple target strength differences be- tween the objects did not account for the dolphin's errors in the E-E condition. In object sets 1 and 3, the elephant and the wood massager (respectively) had distinctively low target strengths ( -46.2 to $-50.9 \mathrm{~dB}$ re $1 \mu \mathrm{Pa}$ ) compared to the other objects in their sets. If the dolphin was using target strength as a primary cue, one would expect confusions between the objects with similar target strengths. This was not the case. For example, in set 1, the elephant's target strength was substantially lower than that of the other two objects whereas those objects' target strengths were similar. However, the objects with similar target strengths were never confused. Helweg et al. (1996) also found good discrimination between objects with similar target strengths.

On the other hand, target strength may have played a role in the confusions the dolphin made in this study. That the two objects in sets 1 and 3 most likely to be involved in confusions, the elephant and the wood massager, both had low target strengths, may have led to lower intensity echoes returning from these objects. Perhaps these soft returns made these objects' echoes more difficult for the dolphin to interpret. As suggested earlier, echoic object recognition requires substantially more information than echoic object detection. Perhaps in these cases the dolphin had trouble getting enough fine-grained information to identify these objects again. Low target strength does not explain performance completely, however, because matching with the elephant was actually quite good overall.

Pattern of changes in the echo train as a function of object orientation. The dolphin's pattern of errors suggests that the pattern of changes in the echo train as a function of object orientation may have been useful for cross-modal matching. Two objects within each set appeared to have a similar pattern of change in target strength across orientations (within the $+15^{\circ}$ to $-15^{\circ}$ range shown in Figure 8), and one object had a distinctive pattern. The majority of the dolphin's errors in the cross-modal conditions in Sets 1 and 3 were confusions between the two objects with similar patterns. In Set 1, the elephant and tip cup had similar patterns in target strength (both had major peaks at the $0^{\circ}$ orientation and minor peaks at the $-13^{\circ}$ orientation) compared to the foam cones (two major peaks at about $0^{\circ}$ and $10^{\circ}$ ). In set 1 the predominant confusion in both the E-V and V-E conditions was between the elephant and cup. In set 3, the tree pan and wood massager had similar patterns in target strength (both relatively minor slope changes) compared to the baby bottle (many sharp slope changes). In set 3 the objects confused most often in the cross-modal conditions were the tree pan and wood massager (59 E-V errors). In set 2 the helmet and the plunger had the most similar patterns in target strength (two peaks versus one peak for the horn). Although the horn and plunger were most often confused in the cross-modal conditions, the helmet and plunger were 
confused second most often (22/59) in the V-E condition.

That the dolphin in this study confused objects with similar patterns of changes in echo trains in the cross-modal conditions suggests that it may be an echo feature that provides the dolphin with information about the object that can be accessed using either vision or echolocation. It is likely that at least some aspects of shape are represented echoically, potentially in an object's pattern of echoic changes across multiple orientations of the object. Theoretical models also suggest that this mechanism would be most likely (e.g., Altes, et al., 2003).

Conclusions from new analyses. The dolphin's higher performance accuracy matching from echoically perceived stimuli to visually perceived stimuli versus from visual stimuli to echoic stimuli suggests that it may be easier to get information echoically that is related to visually accessible object features than the reverse. That more errors occurred with low-target strength objects adds more power to this conclusion because it is probably more difficult to get finetuned object feature information from softer echoes. With difficult objects or tasks, dolphins increase click intensity and the number of clicks presumably to enhance object recognition abilities (Houser et al., 2005; Roitblat et al., 1990).

In terms of discriminable acoustic features, highlight structure (potentially resulting in TSP) appeared to be important for echoic performance; when there were echoic object confusions, the fewest occurred with objects that had distinctive highlight structures (tin cup in set 1 and helmet in set 2). For cross-modal performance, the pattern of changes in echoes from multiple object orientations appeared to be important for recognition; in the cross-modal conditions the dolphin confused objects with similar patterns of changes across orientations (elephant and tin cup, tree pan and wood massager) and did not confuse objects with distinctive patterns of changes (foam cones in set 1 and baby bottle in set $3)$.

\section{Natural Use of Echolocation by Dolphins}

Although we know that dolphins can use echolocation to recognize objects, we do not know the specific purposes to which they put this system in their natural environment. It does not seem to be necessary for prey capture. One blindfolded dolphin, Scylla, engaged in a study of echoic discrimination of objects, was monitored by a battery of 10 hydrophones when a live fish was introduced into her pool (Wood \& Evans, 1980). Although she swam next to the fish and later caught and released it several times when blindfolded, she never emitted echolocation clicks.

Prey detection is a possible use of echolocation but may have substantial costs. The dolphin echolocation system is physically capable of detecting fish, like cod, up to 90 meters away in noisy conditions and up to 173 meters away in quiet conditions (Au, Benoit-Bird, \& Kastelein, 2007). However, echolocation is an active sensory system, and some fish, e.g., American shad, can perceive high-frequency sound (130 $\mathrm{kHz}$ ) including dolphin-like clicks (Mann, Lu, \& Popper, 1997). Such fish may be more likely to evade an actively echolocating dolphin than a quietly swimming one (dos Santos \& Almada, 2004; Gannon, Barros, Nowacek, Read, Waples, \& Wells, 2005; Mann et al., 1997). Several studies of wild bottlenose dolphins suggest that they echolocate fairly infrequently (dos Santos \& Almada, 2004; Gannon et al., 2005).

At present, it appears most likely that dolphins detect potential prey through listening and then echolocate to get more information about them (Gannon et al., 2005). In one playback study to wild dolphins in Sarasota Bay, dolphins oriented and echolocated more after hearing sounds produced by fish versus sounds produced by snapping shrimp or other dolphins or before playback of any sound (Gannon et al., 2005). Wild dolphins tend to echolocate most when they are actively feeding versus engaging in other activities (Jones \& Sayigh, 2002). Currently, no data confirm echoic identification by dolphins of individual fish species. This question, though perhaps technically difficult to address, offers an opportunity for laboratory work to enrich our understanding of dolphin ecology.

\section{General Conclusion}

In summary, dolphins have a remarkable biosonar system that they can use to detect and recognize objects even though echoes are highly variable and strongly affected by multiple environmental factors (Au, 1993). Object matching requires better information than object detection (Roitblat et al., 1990). In noise and with difficult discriminations, dolphins produce more clicks and/or louder clicks and/or higher frequency clicks (Au et al., 1974; Houser et al., 2005; Roitblat et al., 1990). Dolphins can perceive small changes in click echo amplitude, frequency, and duration (Au et al., 1988; Evans, 1973; Thompson \& Herman, 1975).

To discriminate among objects, dolphins may use echo highlights via TSP (Au \& Pawloski, 1989; Au \& Turl, 1991). Dolphins appear to integrate information across click trains (e.g., Altes et al., 2003). They can also eavesdrop on an actively echolocating neighbor's echoes and get enough information to find the object again echoically (Xitco \& Roitblat, 1996).

Dolphins can extract object feature information from echoes that allows them to recognize the same objects presented visually (e.g., Harley et al., 2003). The pattern of changes in echoes across different object orientations may 
provide object feature information (DeLong et al., 2006). The variability of the acoustic features (i.e., target strength, highlight structure, peak frequency, center frequency, bandwidth, and duration) measured for different object orientations would make echoes from a single orientation misleading for object recognition. However, a more stable and thus a more reliable correlate of object features would be the pattern of changes in these acoustic measurements from one orientation to the next. In addition, the variation in these patterns may be more robust as environmental conditions (e.g., water temperature, noise, waves) that affect echoes change.

Clear information about which echo characteristics provide information about specific object features is still needed. For example, we do not know if dolphins can extract holistic shape information from echoes alone. Future work on analysis of echo trains as dolphins perform behavioral experiments should provide more answers about the acoustic features of echoes that provide object feature information. New technology will make such experiments easier to conduct (Houser et al., 2005). Of course, object recognition typically requires multiple sources of information including contextual information used in top-down processing (Roitblat, 2004). Analyses of behavioral data in concert with acoustic information offer a fruitful path for expanding our knowledge of echoic object recognition.

\section{References}

Altes, R.A. (2004). Synthetic aperture and image sharpening models for animal sonar. In J.A. Thomas, C.F. Moss, \& M. Vater (Eds.), Echolocation in Bats and Dolphins (pp. 492-501). Chicago: University of Chicago Press.

Altes, R.A., Dankiewicz, L.A., Moore, P.W., \& Helweg, D.A. (2003). Multiecho processing by an echolocating dolphin. Journal of the Acoustical Society of America, 114, 1155-1166. doi:10.1121/1.1590969

Au, W.W.L. (1993). The Sonar of Dolphins. New York: Springer-Verlag.

Au, W.W.L, Andersen, L.N., Rasmussen, A.R., Roitblat, H.L., \& Nachtigall, P.E. (1995). Neural network modeling of a dolphin's sonar discrimination capabilities. Journal of the Acoustical Society of America, 98, 43-50.

doi: 10.1121/1.413700

Au, W.W.L., Benoit-Bird, K.J., \& Kastelein, R.A. (2007). Modeling the detection range of fish by echolocating bottlenose dolphins and harbor porpoises. Journal of the Acoustical Society of America, 121, 3954-3962.

doi:10.1121/1.2734487

Au, W.W.L., Floyd, R.W., Penner, R.H., \& Murchison, A.E. (1974). Measurement of echolocation signals of the Atlantic bottlenose dolphin, Tursiops truncatus, Montagu, in open waters. Journal of the Acoustical Society of America, $56,1280-1290$.

\section{doi: $10.1121 / 1.1903419$}

Au, W.W.L., \& Hammer, C.E., Jr. (1980). Target recognition via echolocation by Tursiops truncatus. In R.G. Busnel \& J.F. Fish (Eds.), Animal Sonar Systems (pp. 855-858). New York: Plenum Press.

Au, W.W.L. \& Martin, D.W. (1989). Insights into dolphin sonar discrimination capabilities from human listening experiments. Journal of the Acoustical Society of America, 86, 1662-1670. doi:10.1121/1.398596

Au, W.W.L. \& Moore, P.W.B., \& Pawloski, D.A. (1988). Detection of complex echoes in noise by an echolocating dolphin. Journal of the Acoustical Society of America, 83, 662-668. doi:10.1121/1.396161

Au, W.W.L., \& Pawlowski, D.A. (1992). Cylinder wall thickness discrimination by an echolocating dolphin. Journal of Comparative Physiology A, 172, 41-47.

Au, W.W.L., \& Pawloski, J.L. (1989). Detection of noise with rippled spectra by the Atlantic bottlenose dolphin. Journal of the Acoustical Society of America, 86, 591-596.

doi: $10.1121 / 1.398238$

Au, W.W.L., Penner, R.H., \& Kadane, J. (1982). Acoustic behavior of echolocating Atlantic bottlenose dolphins. Journal of the Acoustical Society of America, 71, 1269-1275. doi:10.1121/1.387733

Au, W.W.L., \& Snyder, K.J. (1980). Long-range target detection in open waters by an echolocating Atlantic bottlenose dolphin (Tursiops truncatus). Journal of the Acoustical Society of America, 68, 1077-1084.

doi:10.1121/1.384993

Au, W.W.L. \& Turl, C.W. (1991). Material composition discrimination of cylinders at different aspect angles by an echolocating dolphin. Journal of the Acoustical Society of America, 89, 2448-2451 doi: 10.1121/1.400930

Barta, R.E., (1969). Acoustic pattern discrimination by an Atlantic bottle-nosed dolphin. Unpublished manuscript, Naval Undersea Center, San Diego, California.

Branstetter, B.K., \& Mercado, E. (2006). Sound localization by cetaceans. International Journal of Comparative Psychology, 19, 26-61.

Brownlee, S.M. \& Norris, K.S. (1994). The Acoustic Domain. In K.S. Norris, B. Wursig, R.S. Wells, \& M. Wursig (Eds.), The Hawaiian Spinner Dolphin (pp. 161-185). Los Angeles: University of California Press.

Dankiewicz, L.A., Helweg, D.A., Moore, P.W.B., \& Zafran, J.M. (2002). Discrimination of amplitude-modulated synthetic echo trains by an echolocating bottlenose dolphin. Journal of the Acoustical Society of America, 112, 1702-1708. 이:10.1121/1.1504856 
DeLong, C.M., Au, W.W.L., Harley, H.E., Roitblat, H.L., \& Pytka, L. (2007). Human listeners provide insights into echo features used by dolphins to discriminate among objects. Journal of Comparative Psychology, 121, 306-319 doi:10.1037/0735-7036.121.3.306.

DeLong, C.M., Au, W.W.L., Lemonds, D.W., Harley, H.E., \& Roitblat, H.L. (2006). Acoustic features of objects matched by an echolocating bottlenose dolphin. Journal of the Acoustical Society of America, 119, 1867-1879.

doi:10.1121/1.2161434

DeLong, C.M., Au, W.W.L., \& Stamper, S.A. (2007). Echo features used by human listeners to discriminate among objects that vary in material or wall thickness: Implications for echolocating dolphins. Journal of the Acoustical Society of America, 121, 605-617.

doi: $10.1121 / 1.2400848$

Dos Santos, M.E. \& Almada, V.C. (2004). A case for passive sonar: Analysis of click train production patterns by bottlenose dolphins in a turbid estuary. In J.A. Thomas, C.F. Moss, \& M. Vater (Eds.), Echolocation in Bats and Dolphins (pp. 400-410). Chicago: University of Chicago Press.

Evans, W.E (1973). Echolocation by marine delphinids and one species of fresh-water dolphin. Journal of the Acoustical Society of America, 54, 191-199.

doi:10.1121/1.1913562

Gannon, D.P., Barros, N.B., Nowacek, D.P., Read, A.J., Waples, D.M., \& Wells, R.S. (2005). Prey detection by bottlenose dolphins, Tursiops truncatus: An experimental test of the passive listening hypothesis. Animal Behaviour, 69, 709-720.

doi:10.1016/j.anbehav.2004.06.020

Gaunaurd, G.C., Brill, D., Huang, H., Moore, P.W.B., \& Strifors, H.C. (1998). Signal processing of the echo signatures returned by submerged shells insonified by dolphin "clicks:" Active classification. Journal of the Acoustical Society of America, 103, 1547-1557.

doi:10.1121/1.421302

Glezer, I.L., Hof, P., Morgane, P.J., Fridman, A., Isakova, T., Joseph, D., Nair, A., Parhar, P., Thengampallil, A., Thomas, S., Venugopal, R., \& Jung, G.H. (2004). Chemical neuroanatomy of the inferior colliculus in brains of echolocating and nonecholocating mammals: Immunocytochemical study. In J.A. Thomas, C.F. Moss, \& M. Vater (Eds.), Echolocation in Bats and Dolphins (pp. 161-172). Chicago: University of Chicago Press.

Hammer, C.E., Jr., \& Au, W.W.L. (1980). Porpoise echo-recognition: An analysis of controlling target characteristics. Journal of the Acoustical Society of America, 68, 1285-1293. doi:10.1121/1.385015

Harley, H.E., Putman, E.A., \& Roitblat, H.L. (2003). Bottlenose dolphins perceive object features through echoloca- tion. Nature, 424, 667-669. doi:10.1038/nature01846

Harley, H.E., Roitblat, H.L., \& Nachtigall, P.E. (1996). Object representation in the bottlenose dolphin (Tursiops truncatus): Integration of visual and echoic information. Journal of Experimental Psychology: Animal Behavior Processes, 22, 164-174.

doi:10.1037/0097-7403.22.2.164

Helweg, D.A., Au, W.W.L., Roitblat, H.L., \& Nachtigall, P.E. (1996). Acoustic basis for recognition of aspect-dependent three-dimensional targets by an echolocating bottlenose dolphin. Journal of the Acoustical Society of America, 99, 2409-2420. doi:10.1121/1.415429

Helweg, D.A., Roitblat, H.L., Nachtigall, P.E., \& Hautus, M.J. (1996). Recognition of aspect-dependent three-dimensional objects by an echolocating Atlantic bottlenose dolphin. Journal of Experimental Psychology: Animal Behavior Processes, 22, 19-31. doi:10.1037/0097-7403.22.1.19

Herman, L.M., Hovancik, J.R., Gory, J.D., \& Bradshaw, G.L. (1989). Generalization of visual matching by a bottlenosed dolphin (Tursiops truncatus): Evidence of invariance of cognitive performance with visual and auditory materials. Journal of Experimental Psychology: Animal Behavior Processes, 15, 124-136. doi:10.1037/0097-7403.15.2.124

Herman, L.M., Pack, A.A., \& Hoffmann-Kuhnt, M. (1998). Seeing through sound: Dolphins (Tursiops truncatus) perceive the spatial structure of objects through echolocation. Journal of Comparative Psychology, 112, 292-305.

doi:10.1037/0735-7036.112.3.292

Herman, L.M. Peacock, M.F., Yunker, M.P., \& Madsen, C.J. (1975). Bottlenosed dolphin: Double-slit pupil yields equivalent aerial and underwater diurnal acuity. Science, 189, 650-652. doi:10.1126/science.1162351

Houser, D.S., Helweg, D.A., \& Moore, P.W. (1999). Classification of dolphin echolocation clicks by energy and frequency distributions. Journal of the Acoustical Society, 106, 1579-1585. doi:10.1121/1.427153

Houser, D., Martin, S.W., Bauer, E.J., Phillips, M., Herrin, T., Cross, M., Vidal, A., \& Moore, P.W. (2005). Echolocation characteristics of free-swimming bottlenose dolphins during object detection and identification. Journal of the Acoustical Society of America, 117, 2308-2317. doi: $10.1121 / 1.1867912$

Hunter, G.A. (1988). Visual delayed matching of two-dimensional forms by a bottlenosed dolphin. Unpublished master's thesis. University of Hawaii, Honolulu.

Johnson, C.S. (1967). Sound detection threshohlds in marine mammals. In W. Tavolga (Ed.), Marine Bioacoustics (pp. 247-260). New York: Pergamon Press.

Jones, G.J. \& Sayigh, L.S. (2002). Geographic variation in rates of vocal production of free-ranging bottlenose dol- 
phins. Marine Mammal Science, 18, 374-393. doi:10.1111/j.1748-7692.2002.tb01044.x

Mann, D.A., Lu, Z., \& Popper, A.N. (1997). A clupeid fish can detect ultrasound. Nature, 389, 341.

doi: $10.1038 / 38636$

Marino, L. (1998). A comparison of encephalization between odontocete cetaceans and anthropoid primates. Brain, Behavior, and Evolution, 51, 230-238. doi: $10.1159 / 000006540$

McClellan, M.E., \& Small, A.M. (1965). Time-separation pitch associated with correlated noise bursts. Journal of the Acoustical Society of America, 38, 142-143.

doi:10.1121/1.1909591

Moore, P.W.B, Hall, R.W., Friedl, W.A., \& Nachtigall, P.E. (1984). The critical interval in dolphin echolocation: What is it? Journal of the Acoustical Society of America, 76, 314-317. doi:10.1121/1.391016

Moore, P.W.B., Roitblat, H.L., Penner, R.H., \& Nachtigall, P.E. (1991). Recognizing successive dolphin echoes with an integrator gateway network. Neural Networks, 4, 701709. doi:10.1016/0893-6080(91)90051-6

Nachtigall, P.E. (1980). Odontocete echolocation performance on object size, shape, and material. In R. Busnel and J.F. Fish (Eds.), Animal Sonar Systems (pp. 71-95). New York: Plenum Press.

Pack, A.A. \& Herman, L.M. (1995). Sensory integration in the bottlenosed dolphin: Immediate recognition of complex shapes across the senses of echolocation and vision. Journal of the Acoustical Society of America, 98, 722-733. doi:10.1121/1.413566

Pack, A.A., Herman, L.M., Hoffmann-Kuhnt, M., \& Branstetter, B.K. (2002). The object behind the echo: Dolphins (Tursiops truncatus) perceive object shape globally through echolocation. Behavioural Processes, 58, 1-26. doi:10.1016/S0376-6357(01)00200-5

Roitblat, H.L. (2002). The cognitive dolphin. In M. Bekoff, C. Allen, and G.M. Burghardt (Eds.), The Cognitive Animal (pp. 183-187). Cambridge, MA: MIT Press.

Roitblat, H.L. (2004). Object recognition by dolphins. In J.A. Thomas, C.F. Moss, \& M. Vater (Eds.), Echolocation in Bats and Dolphins (pp. 278-283). Chicago: University of Chicago Press.

Roitblat, H.L., Helweg, D.A., \& Harley, H.E. (1995). Echolocation and imagery. In R.A. Kastelein, J.A. Thomas, and P.E. Nachtigall (Eds.), Sensory Systems of Aquatic Mammals (pp. 171-181). Woerden, The Netherlands: De Spil Publishers.

Roitblat, H.L., Moore, P.W.B., Nachtigall, P.E., \& Penner, R.H. (1991). Natural dolphin echo recognition using an integrator gateway network. Advances in Neural Information Processing Systems, 3, 273-281.

Roitblat, H.L., Penner, R.H., \& Nachtigall, P.E. (1990). Matching-to-sample by an echolocating dolphin (Tursiops truncatus). Journal of Experimental Psychology: Animal Behavior Processes, 16, 85-95.

doi:10.1037/0097-7403.16.1.85

Rose, S.A., \& Orlian, E.K. (1991). Asymmetries in infant cross-modal transfer. Child Development, 62, 706-718. doi: $10.2307 / 1131172$

Thompson, R.K.R. \& Herman, L.M. (1975). Underwater frequency discrimination in the bottlenosed dolphin 1$140 \mathrm{kHz}$ ) and human (1-8 kHz). Journal of the Acoustical Society of America, 57, 943-948.

doi:10.1121/1.380513

Wood, F.G. \& Evans, W.E. (1980). Adaptiveness and ecology of echolocation in toothed whales. In R. Busnel and J.F. Fish (Eds.), Animal Sonar Systems (pp. 381-425). New York: Plenum Press.

Xitco, M.J., Jr., \& Roitblat, H.L. (1996). Object recognition through eavesdropping: Passive echolocation in bottlenose dolphins. Animal Learning \& Behavior, 24, 355-365. 